\title{
Tropical Moist Forest Silviculture and Management : A History of Success and Failure
}

\author{
Authors: H. C. Dawkins and M. S. Philip \\ Publisher: CAB International, UK \\ Year of Publication: 1998 \\ Pages: 359
}

Very little is known about
the beginning of silvicultural operations in forests of the ancient days. No such records as cave paintings, buried artifacts, writings, inscriptions, carvings, ctc. on anyone manipulating forcst vegetation have so far been found. The ancient practice of horticulture which we know from Egypt and Mesopotamia, could be the inspiration to the intelligent dwellers of adjacent forest to do some gardening in the ambient wild vegetation. However, weeding of wild varieties of fruits for their better growth might have preceded the cultivation of gardens, as there is little difference between necding to promote survival and growth of useful young trees occurring naturally in forest and weeding to liberate plants which have been shown.

The (term) Tropical Moist Forest (TMF) that covers all forest types such as tropical wet evergreen; tropical semi-ever grcen and moist deciduous forest of the tropics, encompass an enormous range of precipitation, seasonality, temperatures, relative humidities and the frequency of the extreme climatic features. Their importance to the humanity needs no further mentioning. It must be viewed above the narrow economic arguments. And, their successful silviculture operations should maintain the level of biodiversity, productivity of the site, including soil fertility, hydrological stability and the productivity of the forest biome for timber and other needs of human.

With this background, the learned authors (first author who is unfortunately no more with us), believe that natural forest management can be done through proper silviculture techniques, and conservation and production are not incompatible as some school of ecologists and economists opine. In fact, in some circumstances the only way to conservation will be through the management of the production and services from the forest.

The establishment of certain principles of management and silviculture by Doctor Brandis (botanical, not medical) such as revenue, minimum felling diameter, rctention of seed tree, marking of felling, prefelling treatments, thrifty felling, repair and tending, replacement of felled trees by seedling or dibbling seed and even plantation were seen as the second conservation phase and first period of technical silviculture in the Indian subcontinent. This method which is often been called a 'selection system', if successfully applied, emphasises on regeneration normally by natural seeding, throughout the forest. The system should be seen to have a slight edge over 'the uniform system' in the sense that the latter is a kind of monoculture and may need external input for species such as eucalypt (short age for maturity) which are managed through coppice.

The authors who have nearly fifty years of experience in forestry are in good position to judge the success and failure of tropical moist forest management. Their extensive study on the subject is reflected by the class of the book (except for the exclusion of Nepal's experience on participatory forestry management). The book which is divided into four chapters begins with the early history on exploitative and conservation phases of forests followed by the effect of colonialism in forest management in the Asia-Pacific, Caribbean, the Central and northern South America and Africa. The book, in its chapter 3 , describes about the global exploitative phase which began from the late 1950 s to the mid 1990s. And this is the phase which also saw the beginning of the conservation movement. The chapter is very important in the sense that it gives the details of links between forest policy and management. Also are given the silviculture in selected countries and regions viz. Malaysia, Indonesia, the Philippines Africa, New Zealand, the Caribbean, India 
and the Central America, etc. forest management could bring

The silviculture operations have been lucidly described with highlighting of the role of research in tropical moist forest management.

Finally in the epilogue the authors cite that the failure of a catastrophe to the existing flora and fauna as we know. The foresters who, by nature and by training are conservationists, should bear greater responsiblity in safeguarding all facets of the social- economic- biological system of the tropical forests. One way to address this would be to strengthen integrated management system.

Sushim Ranjan Baral, Ph D

\section{The Endangered Raute Tribe : Ethnobiology and Biodiversity}

Author: Nanda Bahadur Singh

Publisher: Global Research Carrel for Ethnobiology

Year of Publication: 1997

Pages: 144

Prince : NRs 250.00

$\mathbf{R}^{2}$ aute- a group of nomads roam in the forests of west Nepal and India and rely on plant and animal species for their survival. They are found in seventeen places; six in Nepal and eleven in India. Of more than fifty-three different tribal groups, the Rautes is the only ethnic group who has not adopted agriculture as an occupation. Interestingly, some Rautes have been brought into settlement in some place of Dadeldhura District since 1979.

The Rautes live in the forests of Mid and Far Western Development Regions of Nepal. The book mentions that they are one of the last nomadic groups. They hunt monkey and hanuman langur for flesh and collect wild edible plant such as cush-cush and yams. Rautes use 188 plant species and 48 animals for various uses.
This book is divided into eight sections beginning with the general settings, justification, objectives of the research; section two includes the methodology; section three depicts the Raute's ethnography and ethnobiology; section four touches upon the Raute's skills and techniques, conflicts with local people, AIDS and other diseases; section six shows the Raute in the photography; section seven presents concluding remarks; and section eight proposes some recommendations under the heading 'Looking Ahead'. The author has raised some issues like Raute-Rights, Aphorism and establishment of "Human Zoo" which are notable features of this book.

This book is a product of dissertation of M Sc in Zoology of 1993-95 batch. The author has aptly chosen the topic
"Study on Ethnobioligy of the Endangered Tribe, the Rautc in Nepal" and took painstaking efforts to bring out the rescarch findings.

Nepal is a country of multiethnic groups and rich in biodiversity. Study on the ficlds of ethnobiology and biodiversity by a Nepali scholar is a commendable work.

The book is useful for sociologists, biologists, ecologists. It encourages researchers and readers to observe and study the Rautes and other tribes of Nepal, which is important from ecotourism and evolutionary point of view.

Narendra B Khadka Lecturer, Tri Chandar Campus, TU, Kathmandu. 